\title{
Maintenance of Increased Coronary Blood Flow in Excess of Demand by Nisoldipine Administered as an Intravenous Infusion
}

\author{
ALAN L: SOWARD, FRACP, PIM J. De FEYTER, MD, PAUL G. HUGENHOLTZ, MD, \\ and PATRICK W. SERRUYS, MD
}

Systemic and hemodynamic effects of nisoldipine, administered as a $4.5-\mu \mathrm{g} / \mathrm{kg}$ intravenous bolus over 3 minutes followed immediately by an infusion of $0.2 \mu \mathrm{g} / \mathrm{kg} / \mathrm{min}$ over 30 minutes, were studied in 13 patients undergoing diagnostic catheterization for suspected coronary artery disease or follow-up catheterization after coronary angioplasty. Responses to the drug tended to be exaggerated in the first 8 minutes of the infusion, but thereafter produced a steady state, with heart rate increased by $14 \pm 3 \%$ at 16 minutes and by $15 \pm 3 \%$ at 24 minutes $(p<0.05)$, mean aortic pressure de- creased $12 \pm 2 \%$ and $13 \pm 3 \%$ at the same times $(p<0.05)$ and coronary venous blood flow increased by $31 \pm 5 \%$ and $34 \pm 6 \%(p<0.05)$. Myocardial oxygen consumption and the heart ratesystolic aortic pressure product were unchanged and cardiac output and stroke volume were significantly increased. Study during matched coronary sinus pacing produced similar trends. Nisoldipine is a potent coronary and peripheral vasodilator that maintalns an increase in myocardlal oxygen supply in excess of demand when given as an intravenous infusion. f calcium channel blocking agents, dihydropyridine derivates form a distinct subgroup with an overall hemodynamic effect dominated by vasodilation. Nisoldipine, an ester-substituted analog of nifedipine (Fig. 1), exhibits greater smooth muscle selectivity than the parent compound, resulting in more potency as a vasodilator with fewer myocardial depressant effects. ${ }^{1}$ Electrophysiologic effects appear to be minimal at concentrations producing vascular changes. ${ }^{2,3}$ Intravenous nisoldipine administered as a bolus has been studied in humans with suspected coronary artery disease and was found to produce coronary and peripheral vasodilation and to be free of major negative inotropic effects. ${ }^{4,5}$ An increase in coronary blood flow in excess of myocardial oxygen demand was consistently found, and such changes persisted for 20 minutes after acute administration. ${ }^{6}$ Clinical usefulness for paren-

From the Cardiac Catheterization Laboratory, 'I'horaxcenter, Erasmus University, Rotterdam, The Netherlands. Manuscript reccived January 20, 1986; revised manuscript received July 21 , 1986, accepted July 22, 1986.

Address for reprints: Patrick W. Serruys, MD, Catheterization Laboratory, Thoraxcenter, Erasmus University, P.O. Box 1738, 3000 DR Rotterdam, The Netherlands. teral nisoldipine remains to be confirmed, but extrapolation of these studies to disease states suggests that it may be of value in treatment of unstable angina or hypertensive crises. The present study investigates the coronary and systemic effects of nisoldipine given as an intravenous infusion over a 30-minute study period.

\section{Methods}

Thirteen patients ( 10 men, 3 women] with suspected coronary artery disease or undergoing a follow-up study after coronary angioplasty were studied at the time of cardiac catheterization. All cardioactive medications except for $\beta$-adrenergic blocking drugs when used and sublingual nitroglycerin as necded wore discontinued at least 24 hours previously. Any $\beta$-blocking drug was continued in the dosage prescribed by the referring physician. Mean age was 55 years (range 46 to 63). The study protocol was performed before coronary angiography and left ventriculography with the patient fasting and without premedication. No patient required sublingual nitroglycerin in the 12 hours preceding study. A Webster 7Fr continuous thermodilution catheter was inserted into the coronary sinus using a right antecubital approach in 12 patients and a right femoral venous route in 1 patient. A stable position 
TABLE I Patient Clinical and Angiographic Data

\begin{tabular}{|c|c|c|c|c|c|c|c|}
\hline Pt & Age $(y r) \&$ Sex & $\beta$ Blocker & $\begin{array}{l}\text { Dose } \\
\text { (mg) }\end{array}$ & Tíme (hr) & $\begin{array}{c}\text { Healed } \\
\text { AMI }\end{array}$ & CAD & $\begin{array}{l}\text { EF } \\
(\%)\end{array}$ \\
\hline 1 & $61 \mathrm{M}$ & Metoprolol & $2 \times 200$ & 4 & + & 3 & 0.43 \\
\hline 2 & $63 \mathrm{~F}$ & $\ldots$ & & & 0 & 0 & 0.72 \\
\hline 3 & $48 \mathrm{M}$ & $\ldots$ & & & 0 & 1 & \\
\hline 4 & $54 \mathrm{M}$ & $\ldots$ & & & 0 & 1 & 0.74 \\
\hline 5 & $57 \mathrm{M}$ & Metoprolol & $2 \times 50$ & 2 & + & 2 & 0.65 \\
\hline 6 & $60 \mathrm{~F}$ & $\ldots$ & & & 0 & 0 & 0.76 \\
\hline 7 & $55 \mathrm{M}$ & $\ldots$ & & & 0 & 0 & 0.55 \\
\hline 8 & $58 \mathrm{M}$ & Atenolol & $2 \times 100$ & 6 & + & 3 & 0.56 \\
\hline 9 & $58 \mathrm{M}$ & Propranolol & $3 \times 40$ & 4 & + & 1 & 0.61 \\
\hline 10 & $46 M$ & $\ldots$ & & & + & 1 & 0.63 \\
\hline 11 & $51 \mathrm{~F}$ & Atenolol & $1 \times 100$ & 5 & 0 & 0 & 0.78 \\
\hline 12 & $56 \mathrm{M}$ & $\ldots$ & & & 0 & 1 & 0.55 \\
\hline 13 & $47 \mathrm{M}$ & $\ldots$ & & & + & 2 & 0.62 \\
\hline
\end{tabular}

Time (hr) $=$ time in hours between last intake of $\beta$-blocking drug and study.

$\mathrm{AMI}=$ acute myocardial infarction; $\mathrm{CAD}=$ coronary artery disease; $\mathrm{EF}=$ left ventricular ejection fraction.

was achieved and verified by an initial $3-\mathrm{ml}$ contrast injection and subsequent repeated fluoroscopy. Coronary venous blood flow was assessed by thermodilution and the catheter allowed sampling of coronary venous blood for oxygen saturation analysis and cardiac pacing. A Swan-Ganz thermodilution catheter was positioned with the tip at the bifurcation of the main pulmonary artery for cardiac output determination and a 7 Fr pigtail cathetcr was positioned in the ascend-<smiles>CC(=O)CC(C)C</smiles>

NISOLDIPINE<smiles>CCOC(=O)C1=C(C)NC(C)=C(C(=O)OC)C1c1ccccc1[N+](=O)[O-]</smiles>

NIFEDIPINE

FIGURE 1. Chemical structures of the dihydropyridine derivatives nifedipine and nisoldipine. ing aorta for pressure measurements and arterial blood sampling. Baseline measurements were taken during both spontaneous heart rate and coronary venous pacing at a rate approximately 20 beats $/ \mathrm{min}$ above spontaneous rate. In sequence were measured, aortic and coronary venous oxygen saturations, coronary venous blood flow, aortic pressure and cardiac output. Heart rate was determined from continuous electrocardiographic monitoring. Nisoldipine, 4.5 $\mu \mathrm{g} / \mathrm{kg}$, was given as a bolus over 3 minutes through the distal Swan-Ganz catheter lumen and followed immediately by an infusion of $0.2 \mu \mathrm{g} / \mathrm{kg} / \mathrm{min}$ over a 30 minute study period. Care was taken to minimize nisoldipine exposure to light. At times 0,8 and 16 minutes after the bolus of nisoldipine, oxygen saturations and coronary blood flow were determined. At 24 minutes after the bolus, oxygen saturations, coronary blood flow and cardiac output were determined during spontaneous heart rate and at a paced heart rate identical to that chosen for the control measurements. Aortic pressures were recorded at 2-minute intervals during the nisoldipine infusion, blood for nisoldipine levels taken before and $0,8,16$ and 24 minutes after the bolus and hemoglobin concentration determined before and after the study. Calculated parameters of aortic and coronary sinus oxygen contents were given by hemoglobin $(\mathrm{g} / 100 \mathrm{ml}) \times$ oxygen saturation $\times 1.36$, myocardial oxygen consumption by coronary venous blood flow $\times$ aortocoronary sinus oxygen difference and peripheral vascular resistance as the quotient of mean aortic pressure and cardiac output. Coronary vascular resistance was given as the quotient of mean aortic pressure and coronary blood flow. At the completion of the study coronary and left ventricular angiugraphic examinations were performed using standard techniques. Left ventricular ejection fractions were calculated from the right anterior oblique projection using the area-length formula of Dodge.

Statistical analysis: Values reported are mean \pm standard error of the mean, using 2-way analysis of variance (Duncan new multiple-range test) for repeated measurements. When overall significance was found, multiple comparisons were used to delineate 
which paired comparisons were significantly different at the 0.05 level.

\section{Results}

Five of the 13 patients were taking $\beta$-blocking drugs at the time of study. Nine had significant coronary artery disease, defined as at least $50 \%$ luminal diameter narrowing in a major coronary artery, and mean ejection fraction was 0.63 (range 0.43 to 0.78 ). There was no significant difference in hemoglobin levels measured before and after the study. Patient clinical and angiographic data are summarized in Table I. One patient (no. 1) had angina pectoris during control pacing but remained asymptomatic when matched pacing was performed during the nisoldipine infusion. No untoward symptom attributable to the nisoldipine was found in any patient.

Heart rate increased from $71 \pm 4$ to $82 \pm 5[16 \pm 3 \%$, $\mathrm{p}<0.05$ ) at the completion of the bolus and commencement of the $0.2-\mu \mathrm{g} / \mathrm{kg} / \mathrm{min}$ infusion of nisoldipine (time $=0$ minute). The increase was $13 \pm 2 \%$ at 8 (p $<0.05), 14 \pm 3 \%$ at $16(p<0.05)$ and $15 \pm 3 \%$ at 24 minutes ( $p<0.05$ ) (Fig. 2). Initial systolic aortic pressure was $147 \pm 7 \mathrm{~mm} \mathrm{Hg}$ and initial mean aortic pressure was $107 \pm 4 \mathrm{~mm} \mathrm{Hg}$. Nisoldipine produced significant (p <0.05) decreases in systolic aortic pressures of $18 \%$, $14 \%, 15 \%$ and $16 \%$ at times $0,8,16$ and 24 minutes, respectively. Decreases in mean aortic pressure at 0,8 , 16 and 24 minutes were $15 \pm 2 \%, 11 \pm 2 \%, 12 \pm 2 \%$ and $13 \pm 3 \%$, respectively (all p <0.05) (Fig. 2). Cardiac output increased from $5.7 \pm 0.4$ liters $/ \mathrm{min}$ to $7.4 \pm 0.5$ liters/min $(33 \pm 6 \%, \mathrm{p}<0.05)$ after 24 minutes, an

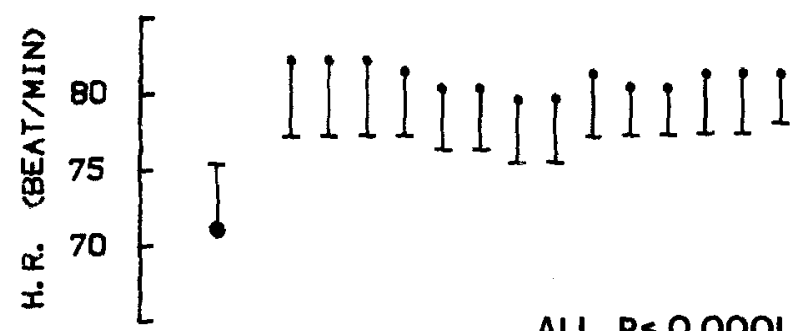

ALL $P<0.0001$

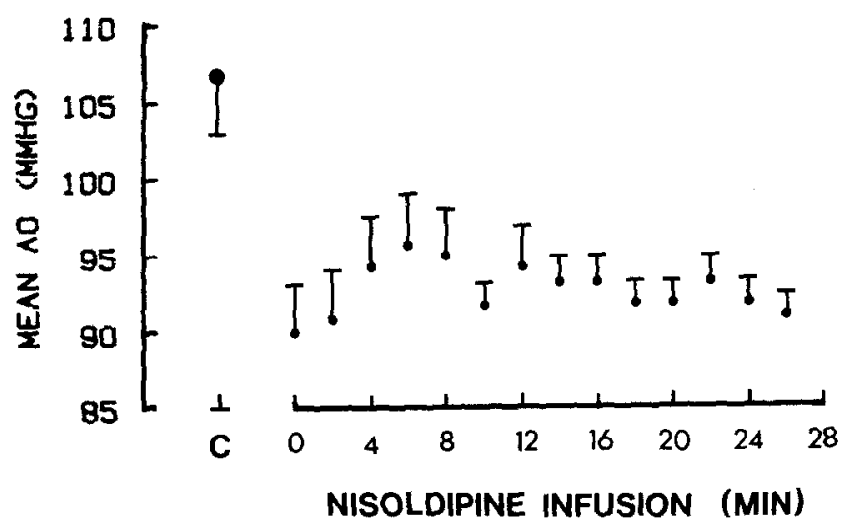

FIGURE 2. Heart rate (H.R.) and mean aortic pressure (AO) before and during nisoldipine infusion. Time 0 represents completion of the bolus of $4.5-\mu \mathrm{g} / \mathrm{kg}$ of nisoldipine over 3 minutes and the immediate commencement of the $0.2-\mu \mathrm{g} / \mathrm{kg} / \mathrm{min}$ inlusion. increase due in part to the heart rate change but also to a $13 \pm 5 \%$ increase in stroke volume $(p<0.05)$. Systemic vascular resistance was simultaneously reduced by $34 \pm 3 \%(\mathrm{p}<0.05)$. Coronary venous blood flow increased from $82 \pm 4 \mathrm{ml} / \mathrm{min}$ to $126 \pm 13 \mathrm{ml} / \mathrm{min}(+51 \pm$ $9 \%, \mathrm{p}<0.05)$ at 0 minute, to $118 \pm 13 \mathrm{ml} / \mathrm{min}(+42 \pm$ $9 \%, \mathrm{p}<0.05)$ at 8 minutes, to $108 \pm 8 \mathrm{ml} / \mathrm{min}(+31 \pm$ $5 \%, \mathrm{p}<0.05)$ at 16 minutes and to $111 \pm 10(+34 \pm 6 \%$, $\mathrm{p}<0.05)$ at 24 minutes after the commencement of the infusion. The decreases in coronary vascular resistance of $42 \pm 5 \%, 35 \pm 6 \%, 33 \pm 3 \%$ and $33 \pm 4 \%$ at the same intervals (all $p<0.05$ ) are illustrated, as are flow increases and myocardial oxygen consumption, in Figure 3. Coronary venous oxygen saturations increased from $46 \pm 1 \%$ to $58 \pm 2 \%$ at 0 minute, $55 \pm 2 \%$ at $8,55 \pm$ $2 \%$ at 16 minutes and $56 \pm 2 \%$ at 24 minutes (all p $<0.05$ ). There was no change in the heart rate-systolic aortic pressure product.

Hemodynamic results during matched coronary venous pacing are listed in Table II.

\section{Discussion}

The peripheral vasodilatory action of the dihydropyridines in reducing left ventricular afterload, when combined with reflex adrenergic stimulation ${ }^{7,8}$ serve to increase cardiac output and mask the intrinsic negative inotropic effects of these compounds apparent in in vitro experiments ${ }^{9}$ and during intracoronary administration..$^{10}$ Reflex adrenergic stimulation may produce

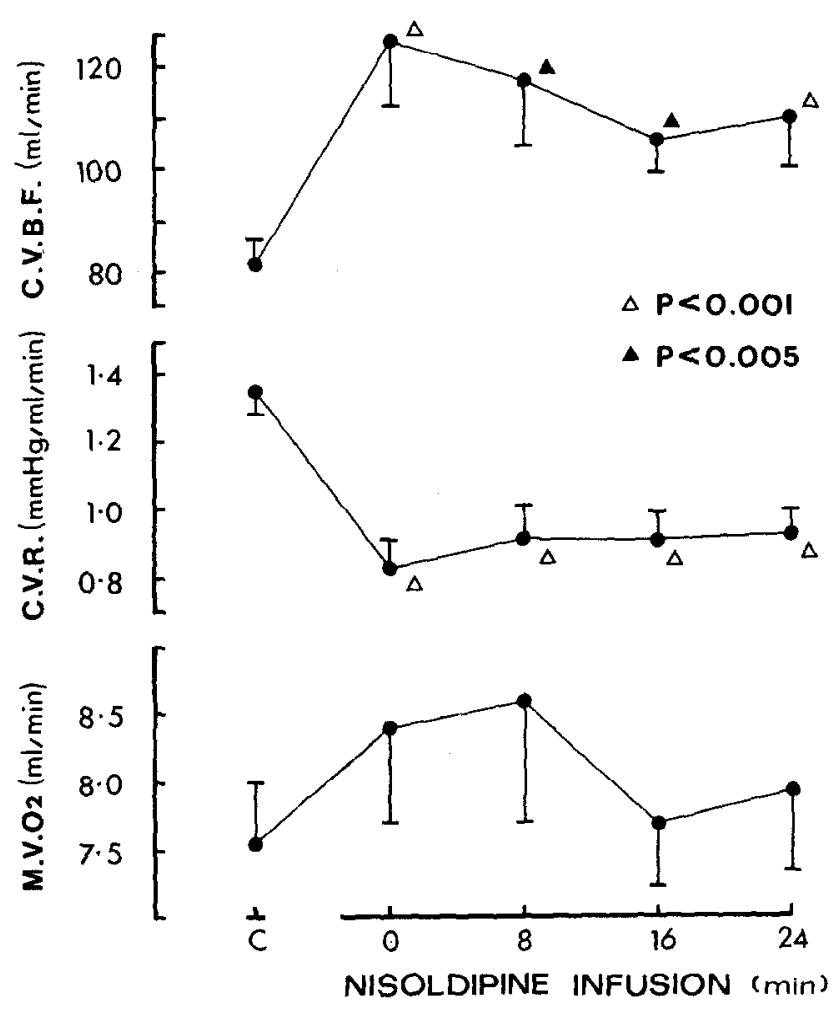

FIGURE 3. Coronary venous blood flow (C.V.B.F.) and calculated coronary vascular resistance (C.V.R.) vs time after commencement of nisoldipine infusion. The lower plot is of myocardial oxygen consumption (M.VO.2). None of the changes in myocardial oxygen consumption were statistically significant. 
TABLE II Hemodynamic Effects During Matched Pacing

\begin{tabular}{lcccc}
\hline & Control & Nisoldipine & \% Change & $p$ Value \\
\hline HR (beats/min) & 91 & 91 & & -17 \\
Systolic Ao $(\mathrm{mm} \mathrm{Hg})$ & $149 \pm 7$ & $123 \pm 3$ & -17 & 0.001 \\
Mean Ao $(\mathrm{mm} \mathrm{Hg})$ & $113 \pm 5$ & $94 \pm 2$ & +26 & 0.001 \\
CO (liters $/ \mathrm{min}$ ) & $6.5 \pm 0.4$ & $8.2 \pm 0.6$ & +24 & 0.0001 \\
SV (ml) & $73 \pm 5$ & $91 \pm 7$ & -34 & 0.005 \\
SVR (dynes s cm & $12 \pm 1$ & +20 & 0.0001 \\
CVBF $(\mathrm{ml} / \mathrm{min})$ & $19 \pm 2$ & $125 \pm 13$ & -26 & 0.05 \\
CVR $\left(\mathrm{mm} \mathrm{Hg} / \mathrm{ml}^{-5} / \mathrm{min}\right)$ & $104 \pm 7$ & $0.85 \pm 0.08$ & -4 & 0.0001 \\
$\mathrm{MVO}_{2}\left(\mathrm{ml} / \mathrm{min} / 10^{-1}\right)$ & $1.15 \pm 0.07$ & $89 \pm 8$ & NS \\
\hline
\end{tabular}

Changes induced by nisoldipine infusion on various parameters during matched coronary sinus pacing.

$\mathrm{AO}=$ aortic pressure; $\mathrm{CO}=$ cardiac output; $\mathrm{CVBF}=$ coronary venous blood flow; $\mathrm{CVR}=$ coronary vascular resistance; $\mathrm{HR}=$ heart rate; $\mathrm{MVO}_{2}=$ myocardial oxygen consumption; $\mathrm{NS}=$ not significant; $\mathrm{SV}=$ stroke volume; SVR $=$ systemic vascular resistance.

an oxygen-wasting effect by increasing inotropic state, as suggested by the increases in calculated myocardial consumption at 0 and 8 minutes after the nisoldipine bolus ( $p=0.07$ and $p=0.06$, respectively). The heart rate-systolic aortic pressure product showed opposite trends (difference not significant [NS]), but this estimation of myocardial oxygen demand is insensitive to changes in inotropic state. Oxygen consumption had returned to control values during infusion at 16 and 24 minutes after the bolus, and was unchanged when heart rate was fixed by matched pacing. Thus, the increase in coronary blood flow during spontaneous heart rate and matched pacing indicates increased myocardial oxygen supply in excess of demand, and these changes may be maintained in a steady state during short-term infusion of nisoldipine.

The nisoldipine infusion produced a stable increase in heart rate and decrease in aortic pressure. The increase in heart rate offsets any reduction in cardiac work secondary to reduced afterload, and this seems a reasonable rationale for combination use with a $\beta$-blocking drug for treatment of hypertension or myocardial ischemia. The 5 patients in the study group taking $\beta$-blocking drugs had smaller increases in heart rate $(11 \%$ vs $17 \%$, NS), a slightly greater decrease in mean aortic pressure $(14 \%$ vs $11 \%$, NS) and a different trend in myocardial oxygen consumption $(-5 \%$ vs $+10 \%$, NS). In anesthetized pigs, the responses to nisoldipine in arterial blood pressure, cardiac output and systemic vascular resistance were unchanged by $\beta$ blockade, but the elevations in heart rate and maximal left ventricular $\mathrm{dP} / \mathrm{dt}$ were abolished, ${ }^{11}$ as was the decrease in left ventricular filling pressure, an effect of nisoldipine shown in other studies. ${ }^{12}$ The decreases in systemic and coronary vascular resistances of $36 \%$ and $31 \%$, respectively, during spontaneous heart rate and decreases of $34 \%$ and $26 \%$ during matched pacing were of similar magnitude and did not support the proposal that nisoldipine exhibits greater coronary vascular than peripheral sensitivity. Nisoldipine has a preferential action and greater potency on vascular smooth muscle than nifedipine, so that vasodilatory changes can be obtained with less tendency to depress myocardial function. These vasodilatory effects with an absence of negative inotropic effects have formed the basis for studies investigating oral nisoldipine in patients with chronic heart failure..$^{13-15}$

Oral nisoldipine has been shown in recent clinical trials to have antianginal properties ${ }^{16-18}$ in patients with stable, exercise-induced angina and in patients with variant angina, ${ }^{19}$ but the value of intravenous nisoldipine in the clinical situation awaits further evaluation. Our study has shown nisoldipine to be a potent coronary and peripheral vasodilator, to increase myocardial oxygen supply in excess of demand and in infusion administration, and to maintain these changes in a stable state over a 30 -minute study period.

Acknowledgment: We are greatly indebted to the nursing and technical staff of the cardiac catheterization laboratory for their skilled assistance in the performance of this study and to Gusta Koster and Anja van Huuksloot for their careful and patient preparation of this manuscript.

\section{References}

1. Kazda S, Garthoff B, Meyer H, Schlossmann K, Stopel K, Towart R, Vater W. Wehinger E. Pharmacology of a new calcium antagonistic compound, isobutyl methyl 1,4-dihydro-2,6-dimethyl-4-(2-nitrophenyl)-3,5-pyridinedicarboxylate [nisoldipine, BAY K 5552). Arzneimittelforsch [Drug Res] 1980; 30(II) 12:2144-2162.

2. Lathrop UA, Valle-Aguilera JR, Millard RW, Guam WE, Hannon DW, Francis PD, Nakaya H, Schwartz A. Comparative electrophysiologic and coronary hemodynamic effects of diltiazem, nisoldipine and verapamil on myocardial tissue. Am I Cardiol 1982;49:613-620.

3. Klein $\mathrm{HH}$, Nordbeck $\mathrm{H}$, Kreuzer $\mathrm{H}$. Effect of the calcium antagonist nisoldipine on electrophysiologic parameters in the human. Z Kardiol 1983;72:180182.

4. Serruys PW, Suryapranata H, Planellas J, Wijns W, Vanhaleweyk GLJ, Soward AL, Jaski BE, Hugenholtz PG. Acute effects of intravenous nisoldipine on left ventricular function and coronary hemodynamics. Am I Cardiol 1985;56:140-146.

5. Suryapranata H, Serruys PW, Soward AL, Planellas J, Vanhaleweyk GLJ, Hugenholtz PG. Acute coronary hemodynamic effects of equihypotensive doses of nisoldipine and diltiazem. Aust NL I Med 1985;15:685-690.

6. Soward AL, de Feyter PJ, Hugenholtz PG, Serruys PW. Coronary and systemic hemodynamic effects of intravenous nisoldipine. Am I Cardiol 1906;50:in press.

7. Maxwell GM, Rencis V. The effects of a new coronary vasodilator (Bay-A1040 , nifedipine) on the coronary and systemic hemodynamics in the anaesthetized dog. Aust I Exp Biol Med Sci 1973;51:117-120.

8. Koch G. Beta-receptor and calcium blockade in ischemic heart disease: effects on systemic and pulmonary hemodynamics and on plasma catecholamines at rest and during exercise. In: Puech $P$, Krebs $R$, eds. Proc 4th Internatl Adalat Symposium. Amsterdam-Oxford: Excerpta Medica, 1980: $131-140$. 
9. De Jong IW, Hiuizer T. Reduced glycolysis by nisoldipine treatment of ischemic heart. J Cardiovasc Pharm 1985;7:497-500.

10. Serruys PW, Brower RW, ten Katen HJ, Bom AH, Hugenholtz PG. Regional wall motion from radiopaque markers after intravenous and intracoronary injection of nifedipine. Circulation 1981;63:584-591.

11. Duncker DI, Hartog IM, Hugenholtz PG, Saxena PR, Verdouw PD. The effects of nisoldipine ( $B A Y K 5552$ ), on cardiovascular performance and regional blood flow, without and after beta-adrenoceptor blockade in penthobarbital anesthetized pigs. Br I Pharmacol 1986;88:9-18.

12. Verdouw $\mathrm{PD}$, Slager $\mathrm{Cl}$ v Bremen $\mathrm{RH}$, Verkeste CM. Is nisoldipine capable of reducing left ventricular preload? Eur I Pharmacol 1984;98:137140

13. Kiowski W, Erne P, Pfisterer M, Müller J, Burkart F. Hemodynamic effects of nisoldipine in patients with ventricular failure (abstr]. Circulation 1985;72:suppl III:III-407.

14. Nienaber CA, Spielman RP, Clausen A. Acute hemodynamic response to intravenous nisoldipine in ischemic cardiomyopathy-comparison with $\mathrm{ni}$ fedipine (abstr). Circulation 1985;72:suppI III:III-407.

15. Kinchi A, Ellrodt, Shah PK, Riedinger MS, Berman DS, Swan HJC, Murata GH. Salutary bemodynamic effects of nisoldipine (BAY K 5552), a new calcium channel blocker, in patients with severe chronic congestive heart failure (abstr). Clin Res 1985;33:10.

16. Lopez LM, Rubin MR, Holland IP, Mehta SL. Improvements in exercise performance with nisoldipine, a new second-generation calcium blocker, in stable angina patients: Am Heart I 1985;110:991-996.

17: Hess OM, Kravenbühl HP. Die antianginöse Wirkung von Calcium-Antagonisten, dargestellt am Beispiel des Nisoldipin. Schweiz Med Wochenschr $1984 ; 114: 1126-1131$

18. Lam J, Chaitman BR, Crean $P$, Blum R, Waters DD. A dose-ranging placebo-controlled, double-blind trial of nisoldipine in effort angina: duration and extent of antianginal effects. JACC 1985;6:447-452

19. Kaski JC, Rodriguez-Plaza L, Maseri A. Nisoldipine: a new calcium antagonist effective in the prevention of coronary artery spasm (abstr). Clin So 1984;67:suppl 9:160. 